INTERNATIONAL DESIGN CONFERENCE - DESIGN 2018

https://doi.org/10.21278/idc.2018.0521

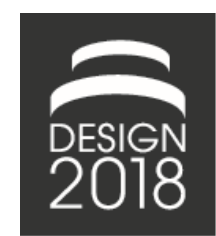

\title{
CORPORATE REQUIREMENT CULTURE IN DEVELOPMENT OF A LARGE SCALE MEDICAL SYSTEM: A CASE STUDY
}

\author{
B. DelSpina, S. Gilliam, J. Summers and B. Morkos
}

\begin{abstract}
This case study explores requirements evolution of a medical device system. The study focuses on the analysis of requirements via interviews and document analysis. The mechanical, software, and systems engineering directors were interviewed regarding eight revisions to the design specifications $(>1000$ total design requirements). Findings suggest 1) change in requirements leadership, 2) market strategy, and 3) requirements writing may lead to requirements change. From analysis, a requirements culture emerged highlighting a need for greater understanding of company requirements cultures in situ.
\end{abstract}

Keywords: engineering change, requirements management, engineering design

\section{Research introduction and motivation}

Requirements change is an active research area for disciplines such as software engineering (Anderson and Felici, 2002; Nurmuliani et al., 2004, 2006; Wen and Dromey, 2004) with various tools developed for the managing of requirements change within software systems (Ibrahim et al., 2009; Ali et al., 2013; Fernández-Alemán et al., 2016). However, a gap exists within the electromechanical field, as its design requirement tools do not adequately address the effects of change on development time and cost (Becerril et al., 2016). Requirement change must therefore be understood to enable the development of such a tool as often those provided by software engineering do not cover the needs of the mechanical design community (Morkos et al., 2012a).

The broad research objective is to examine the evolution of engineering requirements with a focus on the effects of change across requirements revisions to enhance the usability and value added by requirements. This study addresses the question: does a requirement culture exist at the company of study? Requirements driven culture in software engineering is defined as when a company focuses on meeting the "external functional requirements and overall performance characteristics" (Koffi, 2005). An overemphasis on requirements culture can have a negative impact on a company by distancing the developers from the end users (Bryant, 2015).

Requirements change research furthers the discipline's mission by aiming to understand the influences on requirements and means to mitigate their change affects. Requirements change is defined here as the addition, deletion, or modification of existing requirements (Obeidat, 2016). The perspectives of the parties involved with requirements change in large complex projects is still an aspect that is not well understood (Almefelt et al., 2006; Morkos et al., 2010).

As requirements are at the forefront of the design process, the requirements process supports many of the activities in the design process (Tayal, 2013). Over the course of a project, it has been reported that as many as fifty percent or more of a system's requirements may change (Morkos et al., 2012b). Thus, 
in an effort to control costs and other expended resources, understanding of requirements change remains of high significance.

These requirements are not necessarily changed at a single point in time. Rather, a formalized requirement change is initialized via discussion and testing prior to becoming formally documented (Almefelt et al., 2006). However, a complete understanding of engineering changes is not yet recognized (Anderson and Felici, 2002; Felici, 2004; Shankar et al., 2012; Becerril et al., 2016) with findings suggesting that almost one third of an engineer's time can be reduced when appropriate controls are implemented during the change release process (Shankar et al., 2012). A motivation for this research therefore aims to greater understand why requirements change occurs from the perspectives of the involved parties.

By understanding requirements change, requirements may then be used to greater inform projectplanning (Jarratt et al., 2010; Siddiqi et al., 2011; Joshi et al., 2012; Summers et al., 2014; Joshi and Summers, 2015). However, one must first have the ability to anticipate how many requirements are in each category (for example maintenance or operation) and how many more one expects to define (Robertson, 2001), giving rise to the need for a means to gauge project impact resulting from the effects of requirements change. This ability to gauge project completeness and perform impact analysis is especially important in some time critical systems or extended development projects, such as the largescale biomedical system studied.

In summary, the challenge of requirement change is due to the change being stated in the "problem domain", yet the response and employment of the changes occurring being made in the "solution domain" (Wen and Dromey, 2004). By bridging this gap, the goals of this study are to identify and understand the factors of requirement change in the context of a complex technology development, which may contribute to the estimation of impact analysis and project planning.

\section{Case study}

While the greater study comprises both document and interview analysis, this paper addresses the interview analysis alone. The case study methodology has been employed. A case study is defined as a study planned in advance so that data collected may be analysed by others in a way which reduces the opportunity for bias, and is as intimately involved as possible with the phenomena of interest (Yin, 2003; Teegavarapu et al., 2008). Case studies have shown to be a useful research tool, particularly when addressing topics which have previously lacked research attention (MacNealy, 1997). Proponents of the method cite research advantages resulting from its composition of various tools, enabling it to gain greater depth into results, and create a more robust understanding. Finally, case study as a research method has been successfully employed to understand different engineering design phenomena within various contexts. For these reasons, the case study method is used during this research.

The interview portion of the study empirically explores the requirements activities at the company. The focus of the interviews is to develop contextual company background and understanding, something unachievable by retrospective document analysis alone. Specifically, insight was sought into the reasons for requirement change, the company resources in place to support requirements practices, and the requirement impact on the company's process. For anonymity, the interviewees have been assigned uniform gender aliases to avoid bias.

\subsection{Company background}

This study focuses on a U.S based company developing a multimillion-dollar system for cancer treatment, anonymized in this account as MedTech. The iso-certified company, established in 2011, was founded by experts in the field of medical imaging and medical device development. MedTech employs approximately 100 professionals including five systems engineers, twenty mechanical/electrical engineers, five physicists, twenty software engineers, four "dedicated testers", 10-15 people "moonlighting" as testers, and several others performing routine business functions.

MedTech recently received its FDA 510(k) medical device clearance and has one system installation in operation and a second under construction. As still a self-identified "startup", MedTech has remained nimble in its processes. With MedTech's agility, changes are often initiated through informal discussions or meetings, subsequently generating an engineering change notification or other design 
artifact. Within MedTech's environment, an opportunity exists to study requirement change and culture at a medical device developer.

\subsection{Interview study}

Interviews can vary widely being high or low in specificity, lasting for longer or shorter periods of time, and can be highly or loosely structured. This can be seen when asking more open-ended questions, which enables and invites a broader range of answers; or can be closed or targeted, tending to elicit more specific responses which are generally easier analysed. Interviews may be of the unstructured, semistructured, or fully structured framework (Creswell, 2008; Runeson et al., 2012). Unstructured interviews are generally more open and exploratory in nature. Semi-structured tend to have a mix of open and closed questions and aim to be more descriptive and explanatory. They also do not have to be asked in the same order as listed on the interview guide, allowing for greater spontaneity and improvement throughout. Fully structured interviews are generally characterized by their closed questions and descriptive and explanatory aim. These are planned a priori, similar to that of the semistructured framework, yet fully structured interview questions should be asked in the same order as that marked on the interview plan (Runeson et al., 2012).

These semi-structured interviews lasted between 45 and 90 minutes, were audio recorded, and subsequently transcribed. Three interviews were therefore performed within the case study to triangulate upon the high-level causation for requirements change. A summary of the interview approach is captured in Table 1.

Interviewees were first selected using a sampling approach as discussed in (Almefelt et al., 2006). Once interviewees were selected, the individuals were approached with an interviewing request and after subsequent interviewee acceptance, the interview questions were then generated and tested. A subset of the questions asked during the interviews is presented in Table 2, with a complete set found in (DelSpina, 2017). The questions clustered to illustrate triangulation through the "motivation column".

Table 1. Interview summary

\begin{tabular}{|l|l|}
\hline \multicolumn{1}{|c|}{ Item } & \multicolumn{1}{c|}{ Description } \\
\hline Number of Interviewees & Three \\
\hline Description of Interviewees & Engineering Directors \\
\hline Interviewer(s) & Two person team \\
\hline Duration of Interview & 45-90 minutes \\
\hline Period (time frame) of interviews & Spring 2016 \\
\hline Location Description & On-site in the interviewee's office \\
\hline Type of Interview (level of structure) & Semi-structured \\
\hline Materials used during interview & None \\
\hline Selection Strategy & Extensive, systematic sampling approach (Almefelt et al., 2006) \\
\hline Role of Interview in Study & Intentional \\
\hline Additional Methods & Ethnological, document analysis \\
\hline Volume of collected information & Eight DFS, Interview transcripts \\
\hline Verification strategy & Summaries provided to and reviewed by interviewees \\
\hline Recording Strategy & Voice recorder \\
\hline Strategy of Analysis & Triangulation \\
\hline
\end{tabular}

\section{Findings}

Interviews with three of MedTech's directors were conducted. These industry experts span the disciplines of software, biomedical, and systems engineering. These were geared to achieve triangulation onto MedTech's processes of requirements change and propagation mitigation as well as obtain greater situational awareness which is unachievable from document analysis alone. For confidentiality and intellectual property, these transcripts are not included; however, may be made available in redacted form upon request. Anonymized quotations have been implemented in the following discussions. 
Table 2. Subset of interview questions

\begin{tabular}{|c|c|}
\hline Question & Motivation \\
\hline $\begin{array}{l}\text { How much organizational support would you say there is for your work with the } \\
\text { requirements documentation? }\end{array}$ & \multirow{4}{*}{$\begin{array}{l}\text { Obtain insight into } \\
\text { company } \\
\text { requirements culture } \\
\text { from member } \\
\text { perspective }\end{array}$} \\
\hline Do you find that there is general support for your work with requirements? & \\
\hline Has the endorsement for using requirements fluctuated over your time at MedTech? & \\
\hline $\begin{array}{l}\text { What kinds of people (engineers, marketing etc.) or classes (management, directors } \\
\text { etc.) do you find to have the most interest in requirements? }\end{array}$ & \\
\hline $\begin{array}{l}\text { How would you characterize the benefits received to yourself and/or the larger } \\
\text { MedTech company in practicing requirement documentation? }\end{array}$ & \multirow{4}{*}{$\begin{array}{l}\text { Obtain insight into } \\
\text { value placed on } \\
\text { requirements by } \\
\text { personnel }\end{array}$} \\
\hline What is the role of requirements, what are they meant to accomplish? & \\
\hline What do you find to be key components of requirements to make them most useful? & \\
\hline $\begin{array}{l}\text { What are the benefits and advantages of using requirements during the engineering } \\
\text { design and technology development process? }\end{array}$ & \\
\hline $\begin{array}{l}\text { Did you have previous experience or interaction with engineering requirements prior } \\
\text { to coming onboard at MedTech? If so, can you please briefly expand on this? }\end{array}$ & \multirow{4}{*}{$\begin{array}{l}\text { Obtain insight into } \\
\text { employee interaction } \\
\text { with requirements }\end{array}$} \\
\hline $\begin{array}{l}\text { Can you please describe your interaction with the requirements found in } \mathrm{D}^{*} 11 \text { [URS] } \\
\text { and D*345 [DFS]? }\end{array}$ & \\
\hline $\begin{array}{l}\text { Can you recall a specific example where you have referred back to a requirement for } \\
\text { design or testing justification? }\end{array}$ & \\
\hline What is your motivation for interacting with requirements? & \\
\hline $\begin{array}{l}\text { Can you give any insight as to why the large decrease in requirements between } \\
\text { Revisions Three and Four? }\end{array}$ & \multirow{3}{*}{$\begin{array}{l}\text { Obtain insight into } \\
\text { reasons for } \\
\text { requirement change } \\
\text { between revisions }\end{array}$} \\
\hline $\begin{array}{l}\text { Can you please provide insight as to why the large increase in requirements } \\
\text { documentation from Revisions One to Two? }\end{array}$ & \\
\hline $\begin{array}{l}\text { Does MedTech have a defined requirements process? If so can you please direct me } \\
\text { to the document and expand on it? }\end{array}$ & \\
\hline
\end{tabular}

Employing transcription analysis from (Krippendorff, 2004), three influential reasons were uncovered leading to the requirements change: 1) change in requirement leadership, 2) strategic change in regulatory scope, and 3) MedTech's learning curve on requirements; specifically, the need to form and document testable requirements. These are subsequently outlined in the proceeding sub-sections.

\subsection{Requirements comptroller}

Through interviews with the company directors, it was discovered that a shift in requirements ownership occurred when MedTech's current system's engineer took over the document's control. This was also confirmed through document analysis of the Design Functional Specification (DFS) where it was identified that the change took place between Revisions Three and Four (see (DelSpina, 2017)). This was further described by one director who described the document's former owner's understanding of requirements as one which "almost anticipated design" (Tony, 3/8/16), essentially stating a design solution rather than a testable requirement. Similar comments were echoed to the company employed researcher by the company's president outside the interviews, and again during an interview with the company's current systems engineer, Oakley.

\subsection{Government regulation}

Secondly, it was discovered that scope of the regulatory submission was also a major influence in the company's requirements documentation and played a role in the requirements change experienced. This was corroborated by the company's president who stated:

"We used an essential requirements strategy for 510(k) submission; however, all requirements are a part of V\&V prior to first patient treatment." (Micah, 2/28/17) 
Micah has presided over MedTech since its inception in 2011, as well as previously founding another medical company. MedTech has received regulatory clearance since the interviews were conducted, a result of four years of technical development. As guided by government regulators through numerous communications, MedTech enlisted to take a modular approach to the release of its requirements to the government agency. This further contributed to the change observed through document analysis and is corroborated in statements such as:

\begin{abstract}
"There was a timeframe also for in the FDA submission; we are doing this in a modular way. So we are trying to chunk down the pieces given in an orderly fashion that gives them time to, let's say, look at your requirements okay fine. So now let me look at your design and let me look at your test results. So there was a desire to close on the requirements, in time for, in order for us to meet the timeline." (Tony, 3/8/16)
\end{abstract}

\title{
3.3. Requirements learning curve
}

Through triangulation of the interview descriptions and document analysis, a requirements learning curve has also been observed by the researchers and directors. This was disclosed by Tony who stated "certainly the increase in requirements I think is just the fact that we were getting to learn how to write requirements" (Tony, 3/8/16), when questioned as to a possible cause for the increase in requirements from Revisions One to Two. Revision One had 556 requirements, while Revision Two had 786 requirements. Oakley further elaborated on this learning curve stating:

“... a lot of requirements were placed on those designers that probably should have never been there to begin with. I think paying attention to $X, Y$, and $Z$ we're going to force these requirements on you. In the end, those requirements really weren't requirements. They were strong design suggestions." (Oakley, 3/11/16)

In this statement, one can see a learning period was necessary for team members and designers to align their perspectives and objectives to achieve a state of equilibrium. Moreover, it was suggested that the removal of these constraints were a possible reason for the large decrease in requirements observed from Revision Three to Four when the same director stated:

"Some of them weren't requirements at all. They were choices made to implement the design. So they were design outputs instead. Results of doing the design itself and knowing this really was never a requirement to begin with, [rather] a choice you made." (Oakley, 3/11/16)

Elaborating further to the possible cause for requirement reduction between Revisions Five and Six, it was stated that

"A lot of it was the same thing. A lot of it was duplicate requirements, or requirements that were saying essentially the same thing, or things that were at the wrong level." (Oakley, 3/11/16)

Another issue arose within the requirements documentation, that of the need to document testable requirements. While the need to form testable requirements is documented throughout the literature, authorship of testable requirements was a challenge at the company of study. A recent example of this was highlighted in the employee interviews where it was stated:

"I think part of that was actually looking at the tests. I think people didn't realize at some point these requirements need to be testable." (Tony, 3/8/16)

Continuing to this point, Oakley said

"The other thing that has had the biggest impact on change of requirements at the DFS [document] level is how testable they are. What you really don't want is a bunch of subjective requirements because they are very difficult to test. It's really open to the tester to figure out what the heck you're testing, and you don't guarantee that you have a good design. So that's the refinement of requirements that's been done for test purposes. No one was writing test purposes a year ago or two years ago." (Oakley, 3/11/16)

The director went on to state:

“... and now version 6 all [requirements] are being influenced by the way they are going to be tested." (Oakley, 3/11/16) 


\section{Interview analysis discussion}

Cultural differences may be found in the communication, people, activities, and/or values of a group (Dahl, 2004). Symbols, people, and activities are the physical components of a culture. However, the underlying structure of a culture is nonphysical and only discovered through interpretation and communication by its internal members. Over the course of the interviews a requirements culture began to appear. It was found that there appears to be a culture generally centred on the management and formulation of requirements. However, an underlying significance to team values was also discovered which was embodied in the ambiguity of control, regulatory influences, and writing. This layered culture is in line with (Hsieh, 2006) as culture can be decomposed into two levels; a visible behaviour and artefact level and an underlying invisible values level. Values makeup the underlying structure of a culture. Values therefore denote member's thoughts on the way things ought to be and may therefore influence behaviour (Dahl, 2004). Thus, in order to understand a culture one must understand the multiple layers.

\subsection{Requirement control}

Perhaps the challenge of requirement control during early-stage new-product development can be best represented by the director of engineering's comments. When probed about things he would do differently looking back, he stated:

"Knowing what we needed for the core device and really pushing for stakeholder requirements and competitive benchmarks out and marketing benchmarks out and just core device requirements. ... having documents for all these different types of requirements, and having that staged out that would have been a big deal." (Tony, 3/8/16)

The reader can see the worth placed on a concise requirements document by the director, but such a concise document may not have been possible at the earliest development stage of the team. This is a reference to the phenomena of requirements creep stated in literature to denote the tendency of requirements to expand over the course of a project (Young, 2004; NASA, 2010; Ferreira et al., 2011; Oehmen, 2012). This was echoed by MedTech's software engineering director in the statement:

"If we had actually managed our requirements process better we would have saved a lot of time. We would have saved a lot of time and energy. We discovered these things, a little bit the hard way." (Tony, 3/8/16)

This has also been observed in literature. Where, the most influential variable on the cost of requirements stems from change management, with a significant amount of time also spent collecting and finding information which is inconsequential to the accomplishment of activities and tasks (Morkos et al., 2010). This was further triangulated by the company's Systems Engineering director in his statement:

"Very inefficient to do that. [B]ecause then you had fourteen documents floating around that somebody has to go back and do a word compare and look for comments and try to consolidate. Jazz helped a lot with that and made it so there was a database everybody was interacting with in real time." (Oakley, 3/11/16)

As designers look to various knowledge bases including existing and pre-existing project records (Morkos et al., 2010), this is a notable point tying in with comments made by the other directors. As delays are often a result of the time expended during data acquisition (Morkos et al., 2010), the time expended by team members to perform cumbersome document comparisons were both manual and cumbersome, simultaneously not furthering project development. As a result, the company installed state-of-the-art document control and requirements tracing tools and validated them.

From these comments, one can begin to see a general consensus by the directors for clarity on the requirements management practice and the importance of a dedicated requirements comptroller.

\subsection{Regulatory influence}

Requirements documents progress from internal documents in the early stage product development to external documents available to outside government agencies and vendors. This suggests a duality of purpose to requirements. This transmutation may therefore introduce an external regulatory influence into the internal requirement culture, thus not only directing a requirements culture but also forming it. 
There may therefore be a need for both an inward facing requirements culture and outward facing requirements culture, with the company recognizing this duality. Oakley explained the significance of these regulatory documents for the BG-95 stating:

"All those things [regulatory documents] feed into the way we conduct our hazard analysis. When we create it, when we add to it, the way we review it, and how we demonstrate control of the risks that the device proposes." (Oakley, 3/11/16)

The regulatory influence on a developing requirements culture is therefore not inconsequential. Having such deep roots within the "when", "why" and "how" requirements are approached by the company, one can see this regulatory influence may not only direct a developing requirements culture but also shape it.

While this influence may come in the form of explicit guidance such as the regulatory documents described above, it may also influence the development time allotted to the team or company. One director explains this as, "Releasing those [requirements] are kind of tied to some milestones in our company." (Hayden, 3/8/16), referencing the fact that regulatory approval is tied to critical milestones and competitive strategy. Another director explained this as "Some of those revisions are coming from clarity, some of it is driven by the need to close." (Tony, 3/8/16), again referencing the relation between regulatory clearance, competitive strategy, and requirement scope.

The regulatory influence on a developing requirements culture can be seen not only in tangible form such as the guidance documents, but also in a deeper nontangible form such as the timeline imposed when completion of regulatory clearance becomes an organization milestone. A variable to the timeline is scope of user requirements that will directly impact the number of design requirements and validation necessary. As development progresses and the competitive marketplace develops, the scope of requirements should be expected to change. This regulatory influence may therefore not only direct a new requirement culture, but also develop it as requirements transcend from internal to external documents. This duality imposed from transcendence of an internal document to an external document raises the question is there an inward/outward facing requirements culture? To this point, within engineering design literature, little research exists towards the regulatory influence on requirements culture at medical device developers.

\subsection{Requirement writing}

With respect to the writing of requirements, MedTech began with a unique design problem as "There was a pre-existing device that worked well but wasn't ready for distribution or marketing." (Oakley, $3 / 11 / 16)$. The company recognized the need for detailing this problem through requirements. However, MedTech's former comptroller authored solution-based requirements which were untestable, leading to confusion.

This was detailed by the company's current comptroller as:

"A lot of pre-conceptions about what this thing should do... [and] unfortunately the requirements had certainly flowed from that design in some respect. And that's part of why the requirements kept growing because there was ...this pre-conceived notion of a design. ... If we had start perhaps with a concise set of requirements closer to what we have now, things probably would have gone a little faster. I think they definitely would have gone faster." (Oakley, 3/11/16)

In this, the director repeats the notion that the requirements defined the solution. This was again reinforced by a director when he stated, with respect to the requirements:

"I think certainly almost everybody probably appreciates now that the way that we did it originally was not the way it was supposed to be done." (Tony, 3/8/16)

The directors' comments further suggest a learning curve in the requirements writing. This was again repeated by a separate director who recalled company activities where:

"There would be a series of discussions about specs and there would be someone who was like you want me to do what? I don't even know how to test that? It's written so amorphous that it doesn't mean anything to me. So, somebody might say, I can't even test that one system the way that you've written that." (Hayden, $3 / 8 / 16)$ 
This created confusion and frustration with respect to requirements to the point where some saw no real value in engaging with requirements writing until improvements were made in structure and control. Hayden's statement further aligns with interviews conducted in (Almefelt et al., 2006) where it was suggested that the leading issue with respect to the understanding of requirements was the misinterpretation of requirements resulting from their ambiguity. This ambiguity was then found to lead to further issues during the verification phase where the ambiguity produced problems in understanding how to meet or exceed the requirement (Almefelt et al., 2006). This aligns with other researcher's findings that a large quantity of time is expended towards the team synthesis of a mutual cognitive architecture (Curtis et al., 1988).

These comments made by MedTech's directors fall in line with the findings of a study conducted on an automotive company in (Almefelt et al., 2006) where it was found that requirements transform from ambiguous and unstructured statements to greater defined, traceable requirements. It was further found that the greatest issue with respect to the requirements were their interpretation, which lead to confusion resulting from the vagueness of the requirements. The comment made by the company's engineering director, with respect to the test writing of requirements in (Almefelt et al., 2006), further highlights the importance, stating "the meaning of a requirement is dependent on the prescribed verification method" (Almefelt et al., 2006). This comment therefore suggests that testing of the requirement is critical to understanding how to meet or exceed the requirement.

Further, in the early phases prior to the establishment of any formal requirements specification, a preliminary specification was used which was founded on the "state-of-the-art technical knowledge and assumed overall prerequisites" which was also seen to be partial towards solutions. The requirements were not formulated until the solutions were already well known and the automotive development "is characterized by evolution rather than revolution" (Almefelt et al., 2006).

In a study of eleven industries across seven European countries (seven of which had between five and 100 employees, with the remaining four having greater than 100 employees), approximately $70 \%$ of the companies with an in-house or commercial requirements management system controlling more than 1,000 requirements are still not implementing requirements techniques for the extraction or discussion of requirements (Juristo et al., 2002). Reviewing these studies in non-medical device developments, one can see the challenges of requirements writing and ambiguity are not contained to that of medical device developers alone.

\subsection{Summary on requirements culture}

Despite research into requirements engineering practices, companies are largely not adopting these ideals (Morris et al., 1998). This, coupled with the fact that many of the requirements evolution challenges are cultural in nature, suggests the need for further research into current company requirements cultures. This need has further been identified in literature, resulting from intercultural research becoming progressively more important in globalized industry settings (Dahl, 2004). However, in spite of this increasing significance, academics and scholars rarely employ empirical cultural studies to analyze their findings. This lack of use should not be overlooked, as empirical cultural studies are necessary to interpret differences in culture at a deeper level than behavior (Dahl, 2004). Moreover, as no mutually accepted definition of culture or a means to measure it currently exists, a debate persists regarding the soundness of the current data used to define culture and its definition (Dahl, 2004).

In performing requirement culture studies, cultural awareness learned from one environment may assist others in different environments by providing insight into overlapping issues and challenges. As engineering design remains deficient to the complexity of large projects and organizations (Almefelt et al., 2006; Morkos et al., 2010), a major recommendation from this study is that there exists a need to greater understand company cultures in situ, especially as they relate to views and influences on requirements. Similar requirement behaviour was found to exist across medical, avionic (Anderson and Felici, 2002), and automotive domains (Morkos et al., 2012a), irrespective of project size; this work therefore provides quantitative and qualitative insight to the posit that requirement evolution may occur similarly across domain boundaries despite project size.

This study does suggest that a requirement culture exists at MedTech. Justification for this inference can be found when looking to the components of communication, people, symbols, activities, and values 
inherent to a culture, with a requirements culture emphasizing meeting system functionally and performance characteristics.

One can see MedTech's involvement in each cultural aspect. Specifically, MedTech's involvement with requirement meetings, emails, and discussions fulfil the communication component. An example triangulation on the communication component can be seen in Oakley, Hayden, and Tony's comments below.

"This started as a [Microsoft] Word document and so yeah there were lots of Word documents that floated around that were passed to many people and then they would make comments and stick their name or date at the end of it." (Oakley, 3/11/16)

"Every time there was an iteration of these requirements we had a systems engineer that would meet with those individuals that were responsible for that particular design and really kind of hammered in is this requirement what we need and how does it need to be shaped." (Hayden, 3/8/16)

"A new review of the document, it goes to multi- stakeholders for review and it's circulated internally before them." (Tony, 3/8/16)

Reviewing Oakley, Hayden, and Tony's comments above, one can see how the communication component of a requirement culture is fulfilled at MedTech through the performance of communication throughout the departments. Next, the company's personnel involvement of physicists, clinicians, and engineers fulfills the people component of a requirement culture. An example triangulation on the people component can be seen in Oakley, Hayden, and Tony's comments below.

"The systems engineering group here, which is five people, we discuss changes to that document if they are necessary. Looking at ramifications for test and hazard." (Oakley, 3/11/16)

"We had a lot of [domain] experts that really helped shape the product from the beginning. So it was really about getting all the requirements out of their head onto the paper." (Hayden, 3/8/16)

"Definitely there is multi-stakeholder review. So we have for that process all the different areas represented we identify so somebody then can take a look at the change request take a look at the defect and identify where it comes from." (Tony, 3/8/16)

Reviewing Oakley, Hayden, and Tony's comments above, one can see how the people component of a requirement culture is fulfilled through the incorporation of individuals across multiple domains. MedTech's performance of verification and validation (V\&V) consisting of testing, documenting, and output of requirements documents outlining system functionality and performance characteristics fulfills the activities component. An example triangulation on the activities component of a requirement culture can be seen in Micah, Oakley, and Tony's comments below.

"We used an essential requirements strategy for $510(\mathrm{k})$ submission, however, all requirements are a part of V\&V prior to first patient treatment." (Micah, 2/28/17)

"The other thing that has had the biggest impact on change of requirements at the DFS level is how testable they are. What you really don't want is a bunch of subjective requirements because they are very difficult to test... So that's the refinement of requirements that's been done for test purposes. No one was writing test purposes a year ago or two years ago." (Oakley, 3/11/16)

"I think part of that was actually looking at the tests. I think people didn't realize at some point these requirements need to be testable." (Tony, 3/8/16)

Reviewing Micah, Oakley, and Tony's comments, one can see how the activities component of a requirement culture is fulfilled through the importance placed on the activity of verification and validation. Finally, the member's thoughts on how requirements ought to be specific and testable with a shared requirement architecture throughout the company fulfills the underlying value cultural component. An example triangulation on the values aspect of a requirements culture can be seen in Oakley, Hayden, and Tony's comment below.

"In the end those requirements really weren't requirements. They were strong design suggestions. Some of them weren't requirements at all. They were choices made to implement the design. So they were design outputs instead. Results of doing the design itself and knowing this really was never a requirement to begin with. A choice you made." (Oakley, 3/11/16) 
"So there was a requirement must be in metric. Well that's not really an FDA requirement. But manufacturing wanted everything in metric. It's easier for them. So I understand but that's more of a stakeholder requirement. That's what kind of happened over time it just started kind of really trying to deliver and write objective tests to these requirements ... So we can start parsing out what's a stakeholder requirement or a marketing requirement or it's a competitive benchmark. (Hayden, 3/8/16)

"So we paid a little bit of the price there because we had as people now started getting into actually using these requirements it became clear that these were not requirements at all. So we actually had to go through a fairly painful process of retooling our requirements." (Tony, 3/8/16)

Reviewing Oakley, Hayden, and Tony's comment above, one can see how the underlying values aspect of culture is fulfilled through the company's value placed on authoring testable requirements. It should be stated here that the requirements themselves, as analysed in this account, fulfil the symbols cultural component. Recognizing the cultural elements (communication, people, symbols, activities, and values), with an emphasis on meeting system functionality and performance characteristics, it is inferred that a requirement culture exists at the company of study, answering the question "does a requirement culture exist at the company of study?"

Referencing MedTech's inferred requirement culture, one can observe influences from the culture resulting in requirement change, as outlined in this paper. Interview and document analysis findings suggest influences from MedTech's requirement culture on its requirements to be requirement comptroller, government regulation, and requirement learning curve. A shift in requirements comptroller resulting in requirement change suggests an internal governance component to MedTech's requirement culture, as discussed in Sections 3.1 and 4.1. Government regulation prompting change to business and requirement scope suggests an external governance component to the company's requirements culture, as discussed earlier. Team synthesis towards a shared requirement understanding suggests an education component to MedTech's requirement culture. This aligns with the literature, as one can see the criticality and motivation for proper documentation, and facilitation of requirements rooted in a sound requirements culture.

As changes to requirements may result in prolonged development, increased costs, and unnecessary expenditure of company resources, greater understanding of requirements cultures may lead to increased understanding of requirement change influences. An interview protocol is developed for interviews across systems, software, and engineering directors at the company of study, and may be used for replicative studies in other domains. A requirement document analysis protocol is developed for use by other requirement researchers to analyze requirement evolution. This paper therefore begins the foundation for future work in requirements culture research.

\section{Future work}

When surveying current requirements change literature, one can see the predominate area aim to greater understand the change of requirements by looking at the entire specifications document and identifying individual requirements which may be most susceptible to change. However, little effort is expended to understand the phenomena of the change. This is further compounded when one sees the greater need for developing tools and techniques to manage the change. Specifically, a deeper dive is needed into the realm of local requirement change, which could afford a greater global accuracy analysis to be conducted when aiming towards greater requirement change propagation prediction (Morkos et al., 2012a).

Future expansion from this paper could include local syntactical requirement analysis on the MedTech requirement data set using the requirements change propagation predication tool (RCPPT) developed in (Morkos et al., 2012a). In using the RCPPT, nouns, verbs, and user selected keywords may be analyzed to research the ability of requirements to be used to predict requirement change propagation. In this first approach, one may ask the research question can MedTech's medical device requirements be used to predict change propagation at the company of study? Through use of the company's eight requirements documents, consisting of more than 1,000 requirements, one may feed the requirements into the RCPPT to investigate possible relationships between requirements which may aid in the prediction of requirement change propagation. In performing this second approach, one may ask the research question what types of relators exist between MedTech requirements which may predict change propagation at the company of study? In answering this second research question, one may discover relators between MedTech 
requirements which may aid designers in a greater ability to gauge the impact of proposed requirement changes. Requirement relators may exist in the form of part of speech relationships, such as noun, verb, or user selected keyword. In greater understanding these requirement relators, one may then obtain the ability to develop a weighting system to be implemented for the ranking of requirements in terms of likelihood of requirement change. In this, a third research question may be can a weighting system be implemented on MedTech requirements to gauge likelihood of requirement change at the company of study? In approaching this third research question, one may develop a weighting system which characterizes the likelihood of requirement change at the company of study. This weighting system may then be validated on the company's eight requirement revision dataset, and subsequently verified on other requirement datasets such as the Toho, Pierburg, and EVRAZ datasets outlined in (Morkos et al., 2012a). If a pattern is found to exist amongst these industry case studies, one may then wish to impose these three research questions on senior design project requirements to compare and contrast the similarities and differences in senior design requirements with that of industry requirements. This analysis on senior design requirements may then prompt a fourth research question, do senior design project requirements behave similar to that of the MedTech, Toho, Pierburg, and EVRAZ datasets?

\section{References}

Ali, H.O., Rozan, M.Z.A. and Sharif, A.M. (2013), "Change Requirement Management Issues for a Large Software Development Projects”, Journal of Information Systems Research and Innovation, Vol. 5 No. December, pp. 63-69.

Almefelt, L., Berglund, F., Nilsson, P. and Malmqvist, J. (2006), "Requirements management in practice: findings from an empirical study in the automotive industry", Research in Engineering Design, Vol. 17 No. 3, pp. 113134.

Anderson, S. and Felici, M. (2002), "Quantitative aspects of requirements evolution”, 26th Annual International Computer Software and Applications, pp. 27-32.

Becerril, L., Sauer, M. and Lindemann, U. (2016), "Estimating the effects of Engineering Changes in early stage product development", 18th International Dependency and Structure Modeling Conference, DSM 2016, Sao Paulo, Brazil, pp. 125-135.

Bryant, S.T. (2015), User centred engineering in automotive design: A shift from technology-driven product development, Master's thesis, Queensland University of Technology.

Creswell, J.W. (2008), Research Design: Qualitative, Quantitative, and Mixed Methods Approaches, SAGE Publications.

Curtis, B., Herb, K. and Neil, I. (1988), "A field study of the software design process for large systems", Communications of the ACM, Vol. 31 No. 11, pp. 1268-1287.

Dahl, S. (2004), Intercultural Research: The Current State of Knowledge, Middlesex University Business School, London.

DelSpina, B.M. (2017), Requirement Culture at a Large Scale Medical Device Developer : A Case Study, Master's thesis, Clemson University.

Felici, M. (2004), Observational Models of Requirements Evolution, PhD thesis, University of Edinburgh.

Fernández-Alemán, J.L., Carrillo-de-Gea, J.M., Meca, J.V., Ros, J.N., Toval, A. and Idri, A. (2016), "Effects of using requirements catalogs on effectiveness and productivity of requirements specification in a software project management course", IEEE Transactions on Education, Vol. 59 No. 2, pp. 105-118.

Ferreira, S., Shunk, D., Collofello, J., Mackulak, G. and Dueck, A. (2011), "Reducing the Risk of Requirements Volatility: Findings from an Empirical Survey”, Journal of Software: Evolution and Process, Vol. 23 No. 5 , pp. 375-393.

Hsieh, Y. (2006), “Culture and shared understanding in distributed requirements engineering”, Proceedings - 2006 IEEE International Conference on Global Software Engineering, ICGSE 2006, pp. 101-105.

Ibrahim, N., Nasir, W.M., Kadir, W. and Deris, S. (2009), "Simplifying Requirement Change Propagation to Software Design”, 5th International Conference on Information \& Communication Technology and Systems.

Jarratt, T., Eckert, C.M., Caldwell, N. and Clarkson, P.J. (2010), "Engineering change: an overview and perspective on the literature", Research in Engineering Design, Vol. 22 No. 2, pp. 103-124.

Joshi, S. and Summers, J.D. (2015), "Requirements Evolution: Understanding the Type of Changes in Requirement Documents of Novice Designers", ICoRD'15-Research into Design Across Boundaries Volume 2, Bangalore, India, Springer, pp. 471-481.

Joshi, S., Morkos, B. and Summers, J.D. (2012), "Requirements Analysis: Case study with Capstone Design Project", National Capstone Conference 2012, Champaign-Urbana, IL, p. 67. 
Juristo, N., Moreno, A.M. and Silva, A. (2002), "Is the European industry moving toward solving requirements engineering problems?", IEEE Software, Vol. 19 No. December, pp. 70-77.

Koffi, A.D. (2005), "A model for the evolution of software and systems engineering project cultures throughout their life cycles”, Systems Engineering, Vol. 8 No. 2, pp. 151-163.

Krippendorff, K. (2004), Content Analysis: An Introduction to Its Methodology, Content Analysis: An Introduction to Its Methodology, SAGE.

MacNealy, M.S. (1997), "Toward better case study research", IEEE Transactions on Professional Communication, Vol. 40 No. 3, pp. 182-196.

Morkos, B., Joshi, S. and Summers, J.D. (2012a), "Representation: Formal Development and Computational Recognition of Localized Change Types", International Design Engineering Technical Conferences and Computers and Information in Engineering Conference, ASME, Chicago, pp. 1-12.

Morkos, B., Joshi, S., Summers, J.D. and Mocko, G.M. (2010), "Requirements and Data Content Evaluation of Industry In-House Data Management System”, International Design Engineering Technical Conferences and Computers and Information in Engineering Conference, ASME, Montreal, Canada, pp. 493-503.

Morkos, B., Shankar, P. and Summers, J.D. (2012b), "Predicting requirement change propagation, using higher order design structure matrices: an industry case study”, Journal of Engineering Design, Vol. 23 No. 12, pp. 905-26.

Morris, P., Masera, M. and Wilikens, M. (1998), "Requirements engineering and industrial uptake", Requirements Engineering, Vol. 3 No. 2, pp. 79-83.

NASA (2010), NASA Systems Engineering Handbook, DIANE Publishing.

Nurmuliani, N., Zowghi, D. and Powell, S. (2004), "Analysis of requirements volatility during software development life cycle", Proceedings of the 2004 Australian Software Engineering Conference, pp. 28-37.

Nurmuliani, N., Zowghi, D. and Williams, S.P. (2006), "Requirements Volatility and Its Impact on Change Effort: Evidence Based Research in Software Development Projects", Australian Workshop on Requirements Engineering, Adelaide, Australia.

Obeidat, R. (2016), "Managing Requirement Changes in Health Informatics Projects", International Management Review, Vol. 12 No. 1, pp. 39-52.

Oehmen, J. (2012), The Guide to Lean Enablers for Managing Engineering Programs, Joint MIT-PMI-INCOSE Community of Practice on Lean in Program Management, Cambridge, MA.

Robertson, S. (2001), "Requirements trawling: techniques for discovering requirements", International Journal of Human-Computer Studies, Vol. 55 No. 4, pp. 405-421.

Runeson, P., Höst, M., Rainer, A. and Regnell, B. (2012), Case Study Research in Software Engineering, John Wiley \& Sons. https://doi.org/10.1002/9781118181034

Shankar, P., Morkos, B.W. and Summers, J.D. (2012), "Reasons for change propagation: a case study in an automotive OEM", Research in Engineering Design, Vol. 23 No. 4, pp. 291-303.

Siddiqi, A., Bounova, G., de Weck, O.L., Keller, R. and Robinson, B. (2011), “A Posteriori Design Change Analysis for Complex Engineering Projects”, Journal of Mechanical Design, Vol. 133 No. 10, pp. 101005. https://doi.org/10.1115/1.4004379

Summers, J.D., Joshi, S. and Morkos, B. (2014), "Requirements evolution: Relating functional and non-functional requirement change on student project success", ASME 2014 International Design Engineering Technical Conferences and Computers and Information in Engineering Conference, Buffalo, NY, American Society of Mechanical Engineers, pp. V003T04A002.

Tayal, S.P. (2013), "Engineering design process", International Journal of Computer Science and Communication Engineering, Vol. NCRAET-2013, pp. 1-5.

Teegavarapu, S., Summers, J.D. and Mocko, G.M. (2008), "Case study method for design research: A justification”, ASME 2008 International Design Engineering Technical Conferences and Computers and Information in Engineering Conference, Brooklyn, NY, ASME, pp. 495-503.

Wen, L.W.L. and Dromey, R.G. (2004), "From requirements change to design change: a formal path", Proceedings of the Second International Conference on Software Engineering and Formal Methods, 2004. https://doi.org/10.1109/SEFM.2004.1347509

Yin, R. (2003), Case Study Research: Design and Methods, Sage, Thousand Oaks, CA.

Young, R.R. (2004), The Requirements Engineering Handbook, Artech House, Boston.

Dr. Beshoy Morkos, Assistant Professor

Florida Institute of Technology, Mechanical and Aerospace Engineering

150 W. University Blvd., 32901-6982 Melbourne, United States

Email: bmorkos@fit.edu 